\title{
Spatial repellency of metofluthrin-impregnated multilayer paper strip against Aedes albopictus under outdoor conditions, Nagasaki, Japan
}

\author{
Tamara Belzabel Obispo Argueta ${ }^{1)}$, Hitoshi KawadA ${ }^{2)}$ \\ and Masahiro TAKAGI ${ }^{2}$ \\ 1) Ministry of Public Health and Social Assistance, Verbena, Guatemala \\ 2) Department of Vector Ecology \& Environment, Institute of Tropical Medicine, \\ Nagasaki University, Nagasaki, Nagasaki 852-8523 Japan
}

(Receivod: 12 April 2004; Accepted: 28 June 2004)

\begin{abstract}
Spatial repellency of a new device in which metofluthrin, a newly synthesized pyrethroid, is impregnated into a multilayer paper strip, against Aedes albopictus was evaluated under outdoor conditions. High spatial repellency $(>80 \%)$ with the metofluthrin-impregnated $(200 \mathrm{mg})$ device lasted for more than 6 weeks, while the repellency with the same device impregnated with the same amount of transfluthrin declined within 5 weeks after treatment.
\end{abstract}

Key words: Metofluthrin, transfluthrin, Aedes aegypti, Spatial repellency

\section{INTRODUCTION}

Prevention of insect bites has been a long-term problem for humans even in the modern life-style. The problem may be more severe for people living in infectious areas of insect-borne diseases, especially when insects are highly exophagic and anthropophilic. Mosquito coils, mosquito mats, and other formulations, most of which contain pyrethroid insecticides, are broadly and successfully used for the prevention of mosquito bites inside houses. Use of the above devices, however, seems to be limited under outdoor conditions since they sometimes are unable to maintain sufficient aerial concentration of the active ingredient under outdoor conditions. Moreover, their use may be limited in communities where the people have no custom of using them, no electricity, or low standards of living.

Metofluthrin (S-1264) is a newly synthesized pyrethroid, which has strong knockdown and lethal activity against mosquitoes (Shono et al., 2004; Sugano et al., 2004; Ujihara et al., 2004). The vapor pressure of metofluthrin is ca $>2$ times and $>100$ times larger than that of $d$ allethrin and permethrin, respectively, and it vaporizes at normal temperature without heating. These unique characteristics of metofluthrin may lead to new mosquito-controlling devices which need no external energy for vaporization at low cost with long-time efficacy. Kawada et al. (2004a, 2004b) reported the promising efficacy of metofluthrin-impregnated multilayer paper strip against Culex quinquefasciatus Say, Anopheles sundaicus (Rodenwaldt) and $A n$. balabacensis Baisas in Lombok Island, Indonesia. Transfluthrin belongs to the same pyrethroid group as metofluthrin which has high volatility and knockdown activity. Pates et al. (2002) reported the unique attempts using a kerosene oil lamp to vaporize transfluthrin. The above two unique pyrethroids will constitute a new era in the field of spatial repellents for insects, as well as in the field of conventional mos- 
quito-proofing devices. In this paper, we report on the comparative spatial repellent activity of metofluthrin- and transfluthrin-impregnated multilayer paper strip against Aedes albopictus (Skuse) under outdoor conditions.

\section{Materials ANd Methods}

Formulation of metofluthrin- and transfluthrin-impregnated paper strip

Technical grade of metofluthrin, $[(2,3$, 5,6-tetrafluoro-4-methoxy methylbenzyl (E, Z) (1R, 3R)-2,2-dimethyl-3-(prop-2-enyl) cyclopropanecarboxylate)] (99.3\%), and transfluthrin, and multilayer paper strip devices were supplied by Sumitomo Chemical Co., Ltd. (Takatsukasa 4-2-1, Takarazuka, Hyogo, 665-8555 Japan). The paper strip device, which has a multilayer, foldable structure, was treated with 200

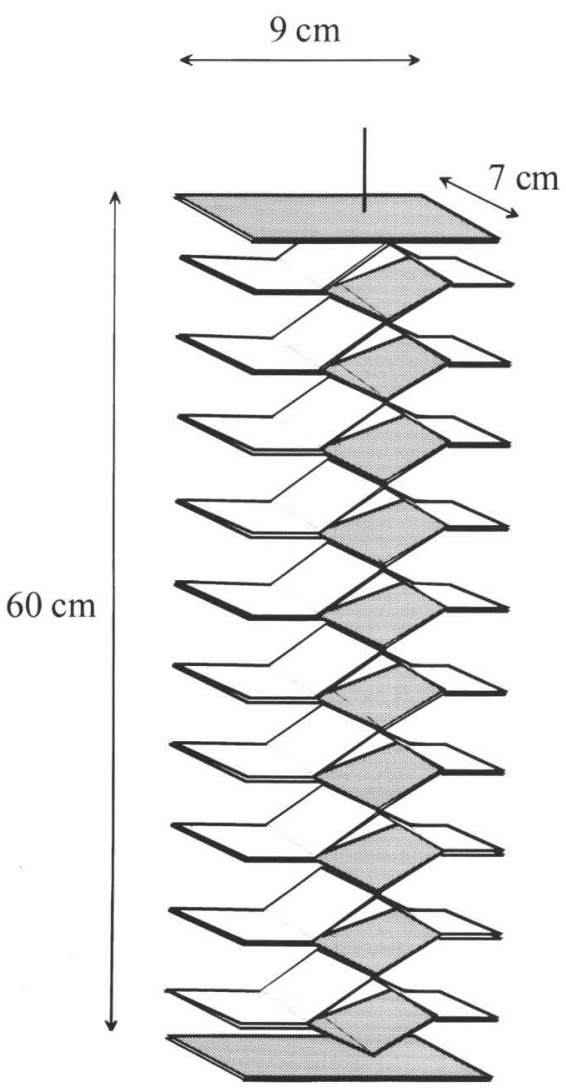

Fig. 1. Insecticide-impregnated multilayer paper strip device used for the test. mg of metofluthrin or transfluthrin diluted with acetone (Fig. 1) and the acetone was vaporized under room conditions. The folded device was compact $\left(63 \mathrm{~cm}^{2}(9\right.$ $\mathrm{cm} \times 7 \mathrm{~cm}$ ) and ca $3 \mathrm{~mm}$ in thickness) and the total surface area of the unfolded paper was ca $2,000 \mathrm{~cm}^{2}$.

Evaluation of spatial repellency of insecticide-impregnated multilayerpaper strips against mosquitoes

The evaluation was carried out on the campus of Nagasaki University (School of Medicine, Nagasaki University, 1-12-4 Sakamoto, Nagasaki, Nagasaki, Japan), from August 11 to October 2, 2003. Two test sites neighboring each other at less than $5 \mathrm{~m}$ distance on the University campus were selected. Sites were both grass-covered and surrounded by vegetation (trees and shrubs). At each site an open tarpaulin was erected to shelter the paper strip devices and collection apparatus from rain and direct sunlight (Fig. 2). The tarpaulin measured ca $5 \mathrm{~m}$ length by ca $3 \mathrm{~m}$ width and was hung from the top of two ca $2 \mathrm{~m}$ high poles. At the lowest point at the edges, the tarpaulin was ca 0.3 $\mathrm{m}$ from the ground. A standard batterypowered CDC-type miniature light trap without light bulbs supplied with dry ice was used to attract and collect mosquitoes. A single CDC-type trap was suspended from a pole placed in the ground in the centre of each test site. Each trap was warmed by a hot-water bag to increase mosquito attractancy. A minimummaximum thermometer was used to monitor the temperature (Fig. 3). The insecticide-impregnated multilayer paper strip devices were first tested fresh, immediately after opening. The devices were aged by hanging in an open outdoor wellventilated rainproof area under eaves. The same devices were retested at intervals for a total of 6 weeks (for transfluthrin-impregnated devices) and 7 weeks (for metofluthrin-impregnated devices). To evaluate the performance of the insecticide-impregnated strips, one strip was 


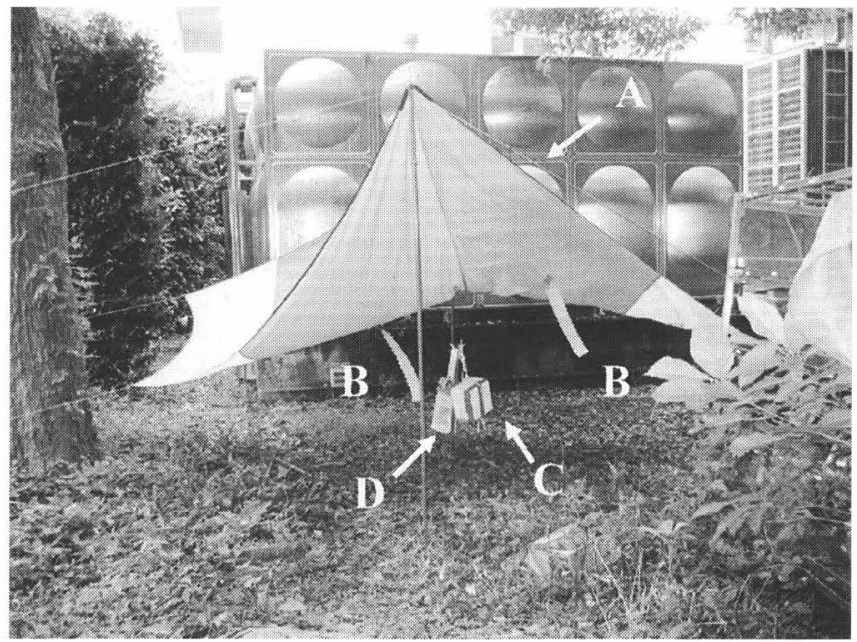

Fig. 2. Outline of field test design. A, Tarpaulin; B, Insecticide-impregnated paper strips; C, Styrofoam box containing dry ice; D, CDC-type miniature mosquito trap.

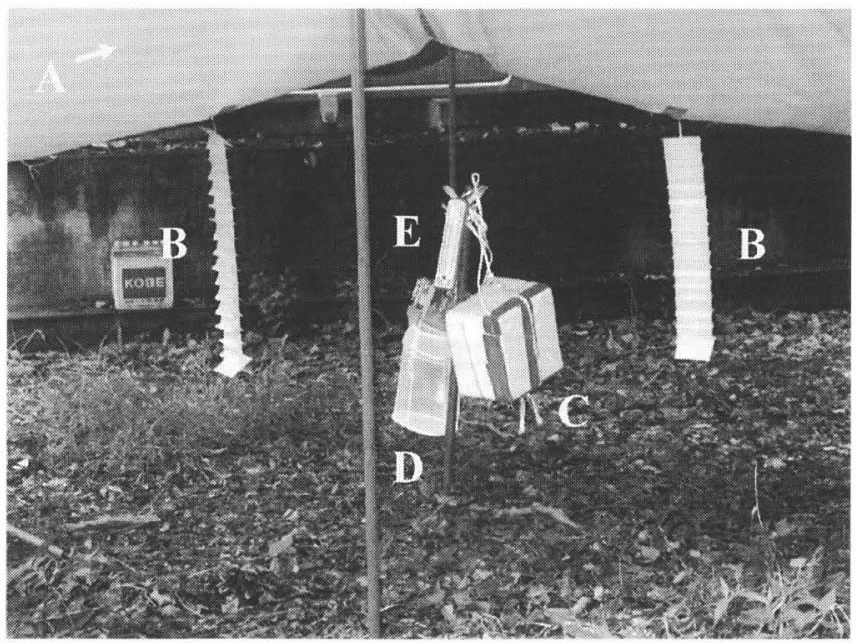

Fig. 3. Outline of test apparatus. A, Tarpaulin; B, Insecticide-impregnated paper strips; C, Styrofoam box containing dry ice; D, CDC-type miniature mosquito trap; E, Minimum-maximum thermometer.

placed on either side of the centre of a tarpaulin, each strip being ca 0.5 meters from the CDC-type trap. At the same time, the other tarpaulin was left untreated with no strips in place. Following one trapping period (from $10: 00$ a.m. to $5: 00$ p.m.) tests were terminated and the following day, tests were repeated with the same insecticide-impregnated strips placed in the other tarpaulin. The test of transfluthrin-4 weeks after treatment was terminated by strong rain on Sept. 12, 2003. A total of one replicate at each site or two replicates over the two sites were thus obtained. Trapped mosquitoes were identified by species and sex and the total number was counted from each trap for each day of the test. The spatial repellency was expressed as reduced \% of the number of mosquitoes in the treated site against the untreated site. Maximum and minimum temperatures were recorded when traps were collected at the end of each test day. 


\section{REsults AND Discussion}

Mosquitoes trapped during the tests were all $A$ e. albopictus with the exception of a single $C x$. pipiens pallens that was caught on August 12, 2003. A high proportion (ca 80\%) of Ae. albopictus collected in the untreated sites was female. Average number of female Ae albopictus collected in the untreated sites was ca 0.68 per hr throughout the test duration, which corresponds well to the collection result of Higa et al. (2000) who reported that the average number of female Ae. albopictus during daytime of September 3 to 12 in the same area as in the present report was 0.69 per hr. Numbers of Ae. albopictus collected in the metofluthrin- and transfluthrin-treated collection sites and untreated sites are shown in Table 1. The results demonstrate that both metofluthrin- and transfluthrin-impregnated paper strips were effective at significantly reducing the numbers of mosquitoes collected. High reductions, ranging from $94.7 \%$ to $100 \%$, compared with untreated sites for metofluthrin-impregnated strips were maintained for 6 weeks after treatment, while a slight decrease in spatial

Table 1. Numbers of Aedes albopictus collected in the metofluthrin and transfluthrin treated outdoor collection sites in Nagasaki, Japan.

\begin{tabular}{|c|c|c|c|c|c|c|c|c|c|}
\hline \multirow{3}{*}{ Samples } & \multirow{3}{*}{$\begin{array}{c}\text { Weeks } \\
\text { After } \\
\text { Treatment }\end{array}$} & \multirow{3}{*}{$\begin{array}{c}\text { Repl. } \\
\text { (Date \& Time) }\end{array}$} & \multirow{2}{*}{\multicolumn{2}{|c|}{$\begin{array}{c}\text { Temperature } \\
\left({ }^{\circ} \mathrm{C}\right)\end{array}$}} & \multicolumn{4}{|c|}{ No. of Collection } & \multirow{3}{*}{$\begin{array}{c}\% \\
- \text { Control }^{1)}\end{array}$} \\
\hline & & & & & \multicolumn{2}{|c|}{ Treated } & \multicolumn{2}{|c|}{ Untreated } & \\
\hline & & & Max. & Min. & Female & Male & Female & Male & \\
\hline \multirow{14}{*}{$\begin{array}{l}\text { Metofluthrin } \\
200 \mathrm{mg}\end{array}$} & \multirow{2}{*}{0} & 1 (Aug. 11, $11: 00-19: 00)$ & 30 & 19 & 0 & 0 & 10 & 8 & \multirow[b]{2}{*}{94.7} \\
\hline & & 2 (Aug. 12, 10:00-17:00) & 31 & 20 & 1 & 0 & 1 & 0 & \\
\hline & \multirow{2}{*}{2} & 1 (Aug. 26, $11: 00-17: 00$ ) & 33 & 20 & 0 & 0 & 7 & 4 & \multirow{2}{*}{100} \\
\hline & & 2 (Aug. 27, $10: 00-17: 00)$ & 33 & 20 & 0 & 0 & 4 & 0 & \\
\hline & \multirow{2}{*}{4} & 1 (Sept. 9, 10:00-17:00) & 30 & 19 & 0 & 0 & 2 & 1 & \multirow{2}{*}{100} \\
\hline & & 2 (Sept. 10, 10:00-17:00) & 31 & 20 & 0 & 0 & 7 & 2 & \\
\hline & \multirow{2}{*}{5} & 1 (Sept. 16, $11: 00-17: 00)$ & 34 & 20 & 0 & 0 & 6 & 1 & \multirow{2}{*}{100} \\
\hline & & 2 (Sept. $17,10: 00-17: 00)$ & 32 & 18 & 0 & 0 & 1 & 0 & \\
\hline & \multirow{2}{*}{6} & 1 (Sept. $22,10: 00-17: 00$ ) & 25 & 21 & 0 & 0 & 8 & 2 & \multirow{2}{*}{100} \\
\hline & & $2($ Sept. $24,10: 00-17: 00)$ & 28 & 22 & 0 & 0 & 1 & 0 & \\
\hline & \multirow{4}{*}{7} & 1 (Sept. 29, $11: 00-17: 00)$ & 23 & 23 & 0 & 0 & 3 & 0 & \multirow{4}{*}{81.8} \\
\hline & & 2 (Sept. 30, 10:00-17:00) & 25 & 21 & 0 & 0 & 0 & 0 & \\
\hline & & 3 (Oct. $\quad 1,10: 00-17: 00$ ) & 27 & 22 & 0 & 1 & 3 & 1 & \\
\hline & & 4 (Oct. $\quad 2,10: 00-17: 00$ ) & 26 & 18 & 1 & 0 & 4 & 0 & \\
\hline \multirow{10}{*}{$\begin{array}{l}\text { Transfluthrin } \\
200 \mathrm{mg}\end{array}$} & \multirow{2}{*}{0} & 1 (Aug. 13, $10: 00-17: 00)$ & 31 & 17 & 0 & 0 & 4 & 3 & \multirow{2}{*}{85.7} \\
\hline & & 2 (Aug. 14, $11: 00-17: 00)$ & 31 & 16 & 1 & 0 & 0 & 0 & \\
\hline & \multirow{2}{*}{2} & 1 (Aug. 28, 10:00-17:00) & 32 & 20 & 1 & 0 & 5 & 0 & \multirow{2}{*}{88.9} \\
\hline & & 2 (Aug. 29, $10: 00-17: 00)$ & 30 & 17 & 0 & 0 & $\begin{array}{c}4 \\
\ldots \ldots\end{array}$ & 0 & \\
\hline & \multirow[b]{2}{*}{4} & 1 (Sept. 11, $11: 00-17: 00)$ & 29 & 19 & 2 & 1 & 11 & 4 & \multirow{2}{*}{43.8} \\
\hline & & $2($ Sept. $12,10: 00-15: 00)$ & - & - & 6 & 0 & 1 & 0 & \\
\hline & \multirow{2}{*}{5} & 1 (Sept. 18, $10: 00-17: 00$ ) & 31 & 19 & 1 & 0 & 10 & 2 & \multirow{2}{*}{70.0} \\
\hline & & $2($ Sept. $19,10: 00-17: 00)$ & 30 & 28 & 5 & 0 & 8 & 0 & \\
\hline & \multirow{2}{*}{6} & 1 (Sept. 25, $10: 00-17: 00$ ) & 22 & 22 & 1 & 0 & 7 & 0 & \\
\hline & & 2 (Sept. 26, 10:00-17:00) & 29 & 22 & 8 & 2 & 2 & 0 & \\
\hline
\end{tabular}

1) $\%$ Control $=($ No. untreated - No, treated $) /$ No. untreated $\times 100$ 
repellency was observed in the 7 th week. In contrast, transfluthrin treatments achieved 85.7 to $43.8 \%$ reductions in a 5 week period, and at the 6 th week failed to reduce trap counts.

The present results indicate that metofluthrin will be one of the most promising chemicals for repelling mosquitoes, as well as transfluthrin. Kawada et al. (2004a, $2004 \mathrm{~b})$ reported that mosquitoes were affected by airborne metofluthrin vapor and not by direct contact to the chemical, resulting in the spatial repellency. The spatial repellency is thought to take place with two main modes of pyrethroid action, i.e., knockdown activity and biting inhibition or disruption of orientation to host. Among them, the latter may be categorized as a sublethal effect resulted from neural excitement, which seems to take place in an earlier stage of toxication or with lower dosage than required for knockdown or death (Birley et al., 1987). Winney (1975) reported that female $A e$. aegypti L. exposed for a few minutes to the smoke of pyrethrum-based mosquito coil did not bite. MacIver (1964) defined the "repellency" associated with pyrethroids to reaction of mosquitoes at the threshold when the neural activation and knockdown occur resulting in the loss of power to orientate their hosts. Similarly, the spatial repellency of metofluthrin-impregnated paper strips is thought to be caused by disruption of orientation activity of mosquitoes.

Use of traditional practices, such as mosquito coils and mats and insecticideimpregnated bed nets, has mainly been focused on the prevention of mosquito biting inside houses (Yap et al., 1990; Aikins et al., 1994; Hewitt et al., 1996). Jensen et al. (2000) reported that only mosquito coils and the deet products did significantly reduce mosquito landing rates in the field among the several commercial anti-mosquito products. Pates et al. (2002) modified the lamp by mixing transfluthrin with vegetable oil and heating it to $120^{\circ} \mathrm{C}$ in a tin can held just above the flame, and more than $90 \%$ protection was achieved with a higher concentration of transfluthrin $(0.5 \%)$, while $0.1 \%$ transfluthrin gave less than $75 \%$ reduction, in the typical houses in Dar es Salaam, Tanzania. Their device will offer a costeffective alternative to mosquito coils and mats, since the kerosene lamps are cheap and broadly used in the tropical area. The above device, however, needs heat for evaporation of solvents and diffusion of active ingredients, which are potential fire hazards, incurs trouble in handling and occasional side effects on human health caused by the smoke. The multilayer paper strip used in the present study is thought to be an ultimate device which needs no external energy for heating and no other materials for evaporation and diffusion of active ingredients at low cost and with high convenience. It is noteworthy that the devices showed significant spatial repellency against Ae. albopictus under open field conditions for more than 6 weeks at $200 \mathrm{mg}$ treatment of metofluthrin for a strip. Further studies on the controlled release of active ingredients will contribute to development of new effective devices for the prevention of outdoor mosquito biting.

\section{ACKNOWLEDGEMENTS}

We express our deep gratitude to Mr. S. Saita, Ms. E. Kawashima and Ms. K. Shimabukuro, Institute of Tropical Medicine, Nagasaki University for supplying the mosquito colony and their assistance in the study. The first author is also grateful to Japan International Cooperation Agency for providing the opportunity to conduct this study and for the financial support in Japan.

\section{REFERENCES}

Aikins, M. K., Pickering, H. and Greenwood, B. M. 1994. Attitudes to malaria, traditional practices and bednets (mosquito nets) as vector control measures: a comparative study in five west African 
countries. J. Trop. Med. Hyg., 97: 81-86.

Birley, M. H., Mutero, C. M., Turner, I. F. and Chadwick, P. R. 1987. The effectiveness of mosquito coils containing esbiothrin under laboratory and field conditions. Ann. Trop. Med. Parasitol., 81: 163-171.

Hewitt, S. E., Farhan, M., Urhaman, H., Muhammad, N., Kamal, M. and Rowland, M.W. 1996. Selfprotection from malaria vectors in Pakistan: an evaluation of popular existing methods and appropriate new techniques in Afghan refugee communities. Ann. Trop. Med. Parasitol., 90: 337-344.

Higa, Y., Tsuda, Y., Tuno, N. and Takagi, M. 2000. Tempo-spatial variation in feeding activity and density of Aedes albopictus (Diptera: Culicidae) at peridomestic habitat in Nagasaki, Japan. Med. Entomol. Zool., 51: 205-209.

Jensen, T., Lampman, R., Slamecka, M. C. and Novak, R. J. 2000. Field efficacy of commercial antimosquito products in Illinois. J. Am. Mosq. Control Assoc., 16: 148-152.

Kawada, H., Maekawa, Y., Tsuda, Y. and Takagi, M. 2004a. Laboratory and field evaluation of spatial repellency with metofluthrin impregnated paper strip against mosquitoes in Lombok Island, Indonesia. J. Am. Mosq. Control Assoc., (in press).

Kawada, H., Maekawa, Y., Tsuda, Y. and Takagi, M. 2004b. Trial of spatial repellency of metofluthrin impregnated paper strip against Anopheles and Culex in shelters without walls in Lombok, Indonesia. J. Am. Mosq. Control Assoc., (in press).

MacIver, D. R. 1964. Mosquito coils Part II. Studies on the action of mosquito coil smoke on mosquitoes. Pyrethrum Post, 7: 7-14.
Pates, H. V., Line, J. D., Keto, A. J. and Miller, J. E. 2002. Personal protection against mosquitoes in Dar es Salaam, Tanzania, by using a kerosene oil lamp to vaporize transfluthrin. Med. Vet. Entomol. 16: $277-284$.

Shono, Y., Kubota, S., Sugano, M., Yap, H. H. and Tsushima, K. 2004. Field evaluation of papers strip and mosquito coil formulation impregnated metofluthrin for mosquito control in Malaysia. In: The Abstract Book, 70th Annual Meeting of the American Mosquito Control Association, p. 40 American Mosquito Control Association, Eatontown, NJ.

Sugano, M., Shono, Y., Ishiwatari, T. and Tsushima, K. 2004. Metofluthrin, new synthetic pyrethroids, an innovative mosquito control agent. In: The Abstract Book, 70th Annual Meeting of the American Mosquito Control Association, p. 6 American Mosquito Control Association, Eatontown, NJ.

Ujihara, K., Mori, T., Iwasaki, T., Sugano, M., Shono, Y. and Matsuo, N. 2004. Metofluthrin: A potent new synthetic pyrethroid with high vapor activity against mosquitoes. Biosci. Biotechnol. Biochem., 68: 170-174.

Winney, R. 1975. Pyrethrins and pyrethroids in coils - a review. Pyrethrum Post, 13: 17-22.

Yap, H. H., Han, H. T., Yahaya, A. M., Baba, R., Loh, P. Y. and Chong, N. L. 1990. Field efficacy of mosquito coil formulations containing $d$-allethrin and $d$-transallethrin against indoor mosquitos especially Culex quinquefasciatus Say. Southeast Asian J. Trop. Med. Public Health, 21: 558-563. 